\title{
COMPARAÇÃO ENTRE ANÁLISE DE TRONCO DIGITAL E CONVENCIONAL EM ÁRVORES DE Mimosa scabrella BENTHAM E Pinus taeda L. ${ }^{1}$
}

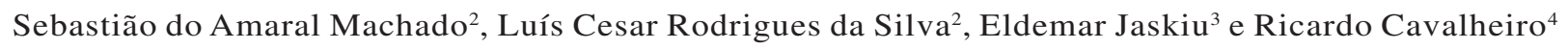

\begin{abstract}
RESUMO - A análise completa de tronco é bastante aplicada em estudos de crescimento de espécies florestais que apresentam anéis de crescimento distinguíveis. As medições dos anéis são feitas manualmente com régua milimetrada, procedimento estabelecido como convencional. Porém, Rosot et al. (2003) desenvolveram procedimentos para que essas medições sejam feitas por programas de computador, trazendo avanço significativo para a aplicação da técnica. Assim, o objetivo deste trabalho foi comparar as medições manuais com as digitais em análise de tronco de Mimosa scabrella e Pinus taeda. Seis árvores de cada espécie foram utilizadas, e as diferenças entre os dois procedimentos para DAP $(\mathrm{cm})$, altura total $(\mathrm{m})$, área transversal $\left(\mathrm{cm}^{2}\right)$ e volume $\left(\mathrm{cm}^{3}\right)$ de cada anel de crescimento foram comparadas com um teste $\mathrm{t}_{(0,05)}$ de dados pareados. As diferenças entre as medições manuais e as digitais foram significativas apenas para o volume do P. taeda em algumas idades. Os resultados indicam que a anatro digital é uma boa opção para a anatro convencional, demandando pessoa treinada para utilizar as ferramentas de Sistema de Informações Geográficas (SIG).
\end{abstract}

Palavras-chave: Anel de crescimento, Bracatinga, Georreferenciamento.

\section{COMPARISON BETWEEN DIGITAL AND CONVENTIONAL STEM ANALYSIS FOR Mimosa scabrella BENTHAM AND Pinus taeda L. TREES}

\begin{abstract}
Complete stem analysis is largely used in studies on the growth of commercial tree species that have distinguishable growth rings. Rings are manually measured, using a millimetric ruler and that is established as standard procedure. However, Rosot et al (2003) developed procedures for these measurements to be made by computer programs, improving significantly the application of this technique. Thus, the objective of this study was to compare manual measurements with digital ones on stem analysis of Mimosa scabrella and Pinus taeda. Six trees of each species were used and the differences between the two procedures for $D B H(\mathrm{~cm})$, total height $(\mathrm{m})$, cross-sectional area $\left(\mathrm{cm}^{2}\right)$ and volume $\left(\mathrm{cm}^{3}\right)$ of each growth ring were compared by the t test (0.05) for paired data. The differences between digital and manual measurements were significant only for the volume of $\mathrm{P}$. taeda in some ages. The results indicate that digital stem analysis is a good alternative to the conventional one, demanding skilled person to use the tools of GIS (Geographic Information System).
\end{abstract}

Keywords: Growth ring, Bracatinga, Georeferencing.

\footnotetext{
${ }^{1}$ Recebido em 06.05.2010 aceito para publicação em 11.03.2013

${ }^{2}$ Departamento de Ciências Florestais, Universidade Federal do Paraná, UFPR, Brasil. E-mail:<samachado@ufpr.br>e $<$ luisnabravo@hotmail.com>.

${ }^{3}$ Programa de Pós-Graduação em Ciências Florestais na Universidade Federal do Paraná, UFPR, Brasil. E-mail: <eldemar_jaskiu@yahoo.com.br>.

${ }^{4}$ Graduação em Engenharia Florestal na Universidade Federal do Paraná, UFPR, Brasil. E-mail:<email:cavalheiro1 @ hotmail.com>.
} 


\section{INTRODUÇÃO}

Os procedimentos para a medição de anéis constituem a parte mais dispendiosa da análise de tronco completa (anatro), muito usada no meio acadêmico e por empresas para estudar a qualidade da madeira e o desenvolvimento de árvores ao longo dos anos (PRODAN et al., 1997). Seus resultados são aplicados em outros estudos que permitem obter projeções de crescimento futuro e tomada de decisões estratégicas para a produção de florestas.

A anatro, feita do modo convencional, vem sendo usada há muito tempo, e sua origem se confunde com os estudos para elaboração das primeiras tabelas de produção comerciais, no fim do século XIX e início do século XX. Envolve a coleta de discos das árvores ao longo de seus fustes e transporte destes para tratamento e posterior medição manual dos anéis de crescimento para, então, proceder-se aos cálculos do crescimento passado.

Há forte tendência no setor florestal para o uso de técnicas de sensoriamento remoto e de processamento digital de imagens, no sentido de aumentar a rapidez e a precisão na obtenção e processamento de dados, especialmente com o emprego de geotecnologias, como afirmaram Rosot et al. (2003). Esses autores também identificaram que a investigação da viabilidade do uso de imagens de discos para avaliar os anéis de crescimento acontece desde 1986.

Atualmente, o que se tem de mais sofisticado no assunto foi apresentado por Ferreira e Tomasello Filho (2009), que diferenciaram anéis de crescimento de Pinus caribaea por densitometria de raios X. Esses autores usaram rolos de incremento, e a densitometria permitiu determinar o limite entre anéis de crescimento por diferenças na densidade das paredes das células presentes nesses limites. O avanço deste trabalho consiste em oferecer a possibilidade de se identificar, com mais segurança, o limite entre os anéis de crescimento e, consequentemente, melhorar a confiabilidade das medições desses anéis. Pode-se dizer ainda que este trabalho abre a possibilidade de aplicar a anatro àquelas espécies arbóreas que apresentam diferenciação no crescimento anual, não distinguível a olho nu, mas identificável através da densitometria, o que ampliaria a aplicabilidade dessa técnica. O inconveniente é que a densitometria é um procedimento caro e a demanda atual por anatro ainda não justifica esse investimento, restringindo a aplicação da densitometria apenas ao meio científico.

A contribuição para a técnica da anatro com maior aplicabilidade é, assim, a de Rosot et al. (2003), que propuseram uma análise de tronco, utilizando fotografia digital de discos, processamento digital de imagens e sistemas de informações geográficas. A técnica foi batizada de análise de tronco digital (anatro digital), e sua grande vantagem consiste em não precisar trazer material do campo, o que elimina os gastos com o tratamento e armazenagem desse material, além do tempo dispensado nessa fase. Esses autores aplicaram a anatro digital em Pinus elliottii, juntamente com a anatro convencional, e observaram que a digital produziu dados do crescimento em volume ao longo dos anos em média $7 \%$ maiores que a convencional. Porém, justificaram que essa diferença pode ter ocorrido em função de se usarem discos recém-cortados na anatro digital, enquanto na anatro convencional se empregam discos após a secagem. Isso leva a crer que não haveria diferenças nos resultados fornecidos pelos dois procedimentos de medição, e a vantagem da anatro digital seria uma informatização total da técnica da anatro, que, a princípio, pode ser mais cara que a convencional, mas com a popularização dos programas de análise envolvidos ou, até mesmo, o desenvolvimento de programas alternativos, ela se tornaria barata e mais prática.

Apesar de Rosot et al. (2003) terem obtido resultados interessantes, cujas diferenças foram atribuídas mais ao fato de se trabalhar com discos secos e lixados na anatro convencional e imagens de discos sem tratamento na anatro digital, ficou a dúvida sobre o ganho que se obtém mudando os procedimentos de medição manuais para digitais.

Assim, o objetivo deste trabalho foi aplicar a anatro digital nas imagens dos discos utilizados na anatro convencional, como forma de igualar os tratamentos e avaliar a real diferença entre os dois procedimentos de anatro das espécies Mimosa scabrella e Pinus taeda.

\section{MATERIAL E MÉTODOS}

\subsection{Origem dos dados}

Os dados da M. scabrella utilizados neste trabalho foram coletados em bracatingais manejados sob o sistema tradicional em propriedades rurais localizadas na região 
metropolitana de Curitiba, mais especificamente no Município de Campina Grande do Sul. Já os dados de P. taeda foram coletados em povoamento estabelecido no Campus III da Universidade Federal do Paraná (UFPR), onde funcionava o Curso de Engenharia Florestal. A região, segundo a classificação de Köeppen, apresenta clima predominantemente $\mathrm{Cfb}$, com temperatura média anual de $16,5^{\circ} \mathrm{C}$, precipitação média anual de 1.500 mm e altitude de aproximadamente $950 \mathrm{~m}$ acima do nível do mar.

\subsection{Análise de tronco convencional}

Foram selecionadas seis árvores de M. scabrella e seis de $P$. taeda. Para cada árvore, foi marcado e medido o diâmetro à altura do peito (dap) e, posteriormente, realizada a derrubada. Sobre a árvore no chão foi esticada uma trena para medir a altura total e foram retirados discos nas alturas de $0,0 \mathrm{~m} ; 0,7 \mathrm{~m} ; 1,30 \mathrm{~m}$; e de 1 em $1 \mathrm{~m}$ até a altura total, resultando em 92 discos de $M$. scabrella e 91 de $P$. taeda. Os discos foram identificados com placas metálicas e levados para secagem em estufa ventilada a $60^{\circ} \mathrm{C}$, por quatro dias. Após a secagem, foi realizado o lixamento da face de medição de cada disco, com máquina e lixa número 80, a fim de facilitar a visualização dos anéis para aplicação da metodologia de análise de tronco tradicional. Os diâmetros de cada anel de crescimento foram medidos usando a metodologia de Barusso (1977), a qual vem sendo adotada em grande parte dos trabalhos de análise de tronco (FINGER, 1992; MACHADO et al., no prelo).

Os dados dos diâmetros a 1,30 m do solo (dap) e a altura total de cada ano de crescimento foram armazenados em planilhas eletrônicas, nas quais foram calculadas as variáveis área transversal e volume. Para o cálculo do volume total em cada idade, foi utilizado o método de Smalian.

\subsection{Análise de tronco digital}

Seguindo os procedimentos adotados por Rosot et al. (2003), cada disco foi estabilizado numa superfície plana e um tripé foi posicionado sobre o disco, a uma distância de 60 a70 cm, dependendo da espessura do disco. Sobre o tripé foi fixada uma câmera digital, de forma que esta ficasse voltada para o disco. Um escalímetro foi posicionado no mesmo nível do disco para servir de escala de referência no posterior processamento da imagem. Finalmente, a imagem do disco foi capturada com resolução de 2.816 x 2.112 pixels, o que equivale a aproximadamente 6.0 MP, a 314 dpi, posicionando o disco no centro da imagem, para evitar as distorções laterais pelo tipo de lente.

As fotos com extensão JPEG foram, então, inseridas no software de processamento de imagens referenciadas ArcView GIS versão 9.2 desenvolvido pelo Environmenal Systems Research Institute (ESRI) e que possui ferramentas que possibilitam análises espaciais de objetos georreferenciados, como foi destacado por Rosot et al. (2003) e pode ser visto na Figura 1.

Procurou-se trabalhar com as imagens sem edição, porém, se ocorresse dificuldade em identificar os limites de cada anel, aplicava-se um realce na imagem para melhorar o contraste, o brilho e a nitidez entre os anéis com o software Microsoft Photo Editor e depois a imagem era novamente inserida no ArcView.

Para obter as áreas transversais de cada anel no disco, foi preciso realizar um procedimento no Arcview, denominado vetorização em tela, que foi feito através do comando start edit e que consistiu em criar, sobre a imagem do disco, linhas de contorno bem no limite

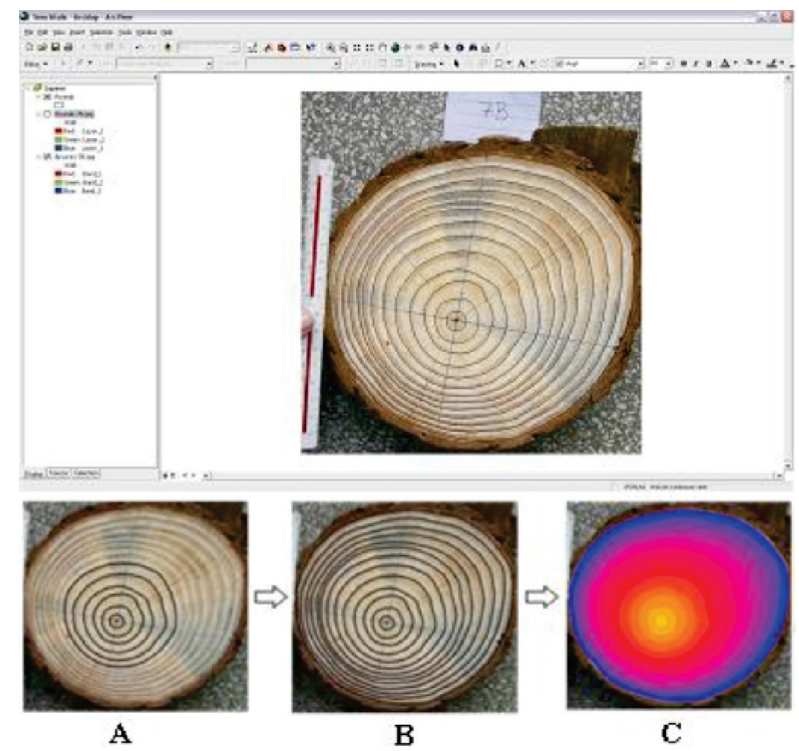

Figura 1 - Janela do software ArcView com a imagem do disco inserida para a determinação do tamanho dos anéis de crescimento e ilustração do processo de vetorização em tela.

Figure 1-ArcView's window, showing the disk cross-section inserted for determination of the growth ring size and vectorizing process illustration to transform growth rings into a shape file.

Revista Árvore, Viçosa-MG, v.37, n.2, p.329-337, 2013 
de cada anel, usando-se o mouse. Em ocasiões em que não havia visualização adequada do fim do anel, aplicou-se um zoom na imagem. Após concluir o contorno em todos os anéis, o resultado foi um arquivo vetorial do ArcView, o shapefile, como passou a ser chamado cada disco, com feição de polígono. O resultado final foi semelhante a um alvo, com vários círculos concêntricos. Esse procedimento está exemplificado na Figura 1, onde em A se destaca o início do processo, com os primeiros anéis circundados, e o resultado em $\mathrm{C}$, com o shapefile já formado e os anéis coloridos para diferenciá-los.

Com o processo de vetorização, criou-se automaticamente uma tabela de atributos, em que se poderiam adicionar colunas para identificação e cálculo da área e do diâmetro de cada anel do shapefile. Porém, a área fornecida pelo ArcView, através do comando returnarea, resultou em dados sem unidade definida, já que a foto do disco não tinha referência, necessitando, então, transformá-los para a escala métrica, com a fórmula adotada por Rosot et al. (2003), sendo:

$$
g=\frac{1}{(F T)^{2}} \cdot g_{s h}
$$

em que $\mathrm{g}=$ área transversal $\mathrm{em} \mathrm{cm}^{2} ; \mathrm{g}_{\mathrm{sh}}$ área sem unidade definida, gerada pelo comando "returnarea"; e FT = fator de transformação, correspondente à relação tamanho na imagem e tamanho real, obtido com o auxílio do escalímetro fotografado junto com o disco.

A tabela de atributos foi, então, exportada para uma planilha Microsoft $t^{\circledR}$ Excel, onde foram efetuados os cálculos da altura e volume em cada idade. Esses dados foram comparados estatisticamente com os dados provenientes de análise de tronco tradicional.

\subsection{Análise estatística adotada}

Foi investigado se, com base na amostra, seria possível detectar diferença entre as duas técnicas e, em caso afirmativo, de quanto. Para isso, foi realizado um teste t pareado, para $\alpha=0,05$. Foram comparados diâmetro, altura, área transversal e volume de cada ano de crescimento. As hipóteses de interesse foram: $\mathrm{H}_{\mathrm{o}}: \mu \mathrm{D}=0$ versus $\mathrm{H}_{\mathrm{a}}$ : e $\mu \mathrm{D} \neq 0$. O teste t escolhido tem a seguinte formulação:

$$
t_{o}=\frac{\bar{D}}{S_{D} / \sqrt{n}}
$$

Revista Árvore, Viçosa-MG, v.37, n.2, p.329-337, 2013 em que:

$\bar{D}=\frac{1}{n} \sum_{i=1}^{n} D_{i}$ é a média das diferenças $S_{\bar{D}}^{2}=\frac{1}{n-1} \sum_{i=1}^{n}\left(D_{i}-\bar{D}\right)^{2}$ a variância das diferenças, em que $\mathrm{D}_{\mathrm{i}}$ é diferença entre a variável obtida pelo método manual e digital, para a idade i; e n é o tamanho da amostra das diferenças.

A hipótese nula foi rejeitada set ${ }_{\mathrm{o}}>\mathrm{t} \alpha / 2 ; \mathrm{n}-1$ ou to $<-$ t $\alpha / 2 ; n-1$. Isso significou $\mathrm{p}-\mathrm{valor}<\alpha$.

\section{RESULTADOS}

As estatísticas para comparação entre a análise de tronco convencional e digital de P. taeda e $M$. scabrella foram reunidos nas Tabelas de 1 a 4 , que apresentam os resumos comparativos das variáveis de cada ano de crescimento.

Os resultados da comparação das alturas de cada ano de crescimento geradas pelos dois procedimentos de anatro são mostrados na Tabela 2, onde se pode observar que não houve diferença significativa, exceto para a idade de 15 anos do $P$. taeda, provavelmente em função do baixo número de árvores com essa idade, não representando adequadamente a variação da população.

Optou-se por utilizar a área transversal em centímetros quadrados e o volume em centímetros cúbicos, porque a área transversal em metros quadrados e o volume em metros cúbicos, como é habitual apresentar, continham concentração de números muito próximos a zero, dificultando avaliações e apresentação dos resultados (Tabelas 3 e 4).

\section{DISCUSSÕES}

Imagens de 6,0 megapixels de tamanho e 314 dpi de resolução permitiram a aproximação com nitidez excelente e foi muito útil para tirar dúvidas dos limites dos anéis de crescimento, não necessitando submeter as imagens à reforço de contraste, nitidez ou brilho. Rosot et al. (2003) usaram imagens de até 3,0 megapixels e recomendaram o uso de cartões com bastante memória quando as imagens forem tomadas, além de ter opções para armazenar essas imagens já no campo usando-se um laptop. Como na técnica da anatro digital os discos não foram trazidos do campo, faz sentido fotografá-los várias vezes com resolução alta e armazenar as imagens de forma segura, para diminuir os riscos de perdê-las e ter alternativas para as que não ficarem boas. 
Tabela 1 - Resumo das análises das diferenças entre anatro convencional e digital para Mimosa scabrella e Pinus taeda, ao nível do dap (cm).

Table 1 - Summary of the analyses of differences between conventional and digital stem analysis for Mimosa scabrella and Pinus taeda trees, at DBH (cm) level.

\begin{tabular}{|c|c|c|c|c|c|c|c|c|c|c|c|c|c|c|}
\hline \multicolumn{8}{|c|}{ Mimosa scabrella } & \multicolumn{7}{|c|}{ Pinus taeda } \\
\hline $\begin{array}{l}\text { Idade } \\
\text { (ano) }\end{array}$ & $\begin{array}{l}\text { No. } \\
\text { Arv. }\end{array}$ & $\begin{array}{l}\text { Menor } \\
\text { desvio }\end{array}$ & $\begin{array}{l}\text { Maior } \\
\text { desvio }\end{array}$ & $\begin{array}{l}\text { Desvio } \\
\text { médio }\end{array}$ & $\begin{array}{l}\text { Desvio } \\
\text { padrão }\end{array}$ & $\mathrm{t}_{(0,05)}$ & $p$ & $\begin{array}{l}\text { No. } \\
\text { Arv. }\end{array}$ & $\begin{array}{l}\text { Menor } \\
\text { desvio }\end{array}$ & $\begin{array}{l}\text { Maior } \\
\text { desvio }\end{array}$ & $\begin{array}{l}\text { Desvio } \\
\text { médio }\end{array}$ & $\begin{array}{l}\text { Desvio } \\
\text { padrão }\end{array}$ & $\mathrm{t}_{(0,05)}$ & $p$ \\
\hline & & $(\mathrm{cm})$ & $(\mathrm{cm})$ & $\%$ & $(\mathrm{~cm})$ & & & & $(\mathrm{cm})$ & $(\mathrm{cm})$ & $\%$ & $(\mathrm{~cm})$ & & \\
\hline 1 & 5 & $-0,40$ & 0,35 & 2,68 & 0,27 & $0,06^{\mathrm{ns}}$ & 0,95 & 1 & 0,05 & 0,05 & - & - & - & - \\
\hline 2 & 6 & $-0,35$ & 0,20 & $-0,49$ & 0,24 & $-0,21^{\mathrm{ns}}$ & 0,84 & 6 & $-0,34$ & 0,03 & $-8,02$ & 0,15 & $-2,45^{\mathrm{ns}}$ & 0,06 \\
\hline 3 & 6 & $-0,50$ & 0,10 & $-1,44$ & 0,22 & $-1,01^{\mathrm{ns}}$ & 0,36 & 6 & $-0,39$ & 0,29 & $-1,94$ & 0,22 & $-0,81^{\mathrm{ns}}$ & 0,45 \\
\hline 4 & 6 & $-0,45$ & 0,15 & $-1,63$ & 0,20 & $-1,58^{\mathrm{ns}}$ & 0,17 & 6 & $-0,09$ & 0,08 & $-0,07$ & 0,07 & $-0,14^{\mathrm{ns}}$ & 0,90 \\
\hline 5 & 6 & $-0,17$ & 0,25 & 0,68 & 0,16 & $-1,10^{\mathrm{ns}}$ & 0,32 & 6 & $-0,14$ & 0,08 & $-0,56$ & 0,09 & $-1,07^{\mathrm{ns}}$ & 0,34 \\
\hline 6 & 6 & $-0,16$ & 0,15 & $-0,83$ & 0,11 & $-1,33^{\text {ns }}$ & 0,24 & 6 & $-0,16$ & 0,22 & $-0,26$ & 0,15 & $-0,34^{\mathrm{ns}}$ & 0,75 \\
\hline 7 & 6 & $-0,17$ & 0,25 & 0,15 & 0,14 & $-0,40^{\mathrm{ns}}$ & 0,70 & 6 & $-0,19$ & 0,19 & $-0,39$ & 0,14 & $-0,63^{\mathrm{ns}}$ & 0,56 \\
\hline 8 & 6 & $-0,20$ & 0,10 & $-0,86$ & 0,11 & $-1,84^{\mathrm{ns}}$ & 0,12 & 6 & $-0,24$ & 0,23 & $-0,09$ & 0,19 & $-0,12^{\mathrm{ns}}$ & 0,91 \\
\hline 9 & 6 & $-0,20$ & 0,10 & $-0,83$ & 0,14 & $-1,23^{\mathrm{ns}}$ & 0,27 & 6 & $-0,24$ & 0,13 & $-0,79$ & 0,15 & $-1,48^{\mathrm{ns}}$ & 0,20 \\
\hline 10 & 6 & $-0,50$ & 0,35 & $-1,13$ & 0,28 & $-0,85^{\text {ns }}$ & 0,43 & 6 & $-0,28$ & 0,09 & $-1,09$ & 0,17 & $-1,98^{\mathrm{ns}}$ & 0,10 \\
\hline 11 & 5 & $-0,60$ & 0,25 & $-1,69$ & 0,31 & $-1,31^{\mathrm{ns}}$ & 0,26 & 6 & $-0,29$ & 0,10 & $-0,91$ & 0,17 & $-1,74^{\mathrm{ns}}$ & 0,14 \\
\hline 12 & - & - & - & - & - & - & - & 5 & $-0,30$ & 0,14 & $-0,82$ & 0,20 & $-1,23^{\mathrm{ns}}$ & 0,29 \\
\hline 13 & - & - & - & - & - & - & - & 5 & $-0,31$ & 0,08 & $-0,85$ & 0,18 & $-1,46^{\mathrm{ns}}$ & 0,22 \\
\hline 14 & - & - & - & - & - & - & - & 4 & $-0,30$ & 0,11 & $-0,81$ & 0,22 & $-0,98^{\mathrm{ns}}$ & 0,40 \\
\hline \multicolumn{2}{|c|}{ Media } & $-0,34$ & 0,20 & $-0,49$ & 0,20 & - & - & - & $-0,25$ & 0,14 & $-1,28$ & 0,16 & - & - \\
\hline
\end{tabular}

No. Arv. é o número de árvores que apresentam de uma dada idade, ns teste não significativo a 5\%, * teste significativo a 5\%; ** teste significativo a $1 \%$.

Tabela 2 - Resumo das análises das diferenças entre anatro convencional e digital para Mimosa scabrella e Pinus taeda, ao nível das alturas de crescimento anual.

Table 2 - Summary of the analyses of differences between conventional and digital stem analysis for Mimosa scabrella and Pinus taeda trees, at the level of annual growth height.

\begin{tabular}{|c|c|c|c|c|c|c|c|c|c|c|c|c|c|c|}
\hline \multicolumn{8}{|c|}{ Mimosa scabrella } & \multicolumn{7}{|c|}{ Pinus taeda } \\
\hline $\begin{array}{l}\text { Idade } \\
\text { (ano) }\end{array}$ & $\begin{array}{l}\text { No. } \\
\text { Arv. }\end{array}$ & $\begin{array}{l}\text { Menor } \\
\text { desvio }\end{array}$ & $\begin{array}{l}\text { Maior } \\
\text { desvio }\end{array}$ & $\begin{array}{l}\text { Desvio } \\
\text { médio }\end{array}$ & $\begin{array}{l}\text { Desvio } \\
\text { padrão }\end{array}$ & $\mathrm{t}_{(0,05)}$ & $p$ & $\begin{array}{l}\text { No. } \\
\text { Arv. }\end{array}$ & $\begin{array}{l}\text { Menor } \\
\text { desvio }\end{array}$ & $\begin{array}{l}\text { Maior } \\
\text { desvio }\end{array}$ & $\begin{array}{l}\text { Desvio } \\
\text { médio }\end{array}$ & $\begin{array}{l}\text { Desvio } \\
\text { padrão }\end{array}$ & $\mathrm{t}_{(0,05)}$ & $p$ \\
\hline & & $(\mathrm{cm})$ & $(\mathrm{cm})$ & $\%$ & $(\mathrm{~cm})$ & & & & $(\mathrm{cm})$ & $(\mathrm{cm})$ & $\%$ & $(\mathrm{~cm})$ & & \\
\hline 1 & 6 & 0,00 & 0,00 & 0,00 & 0,0 & - & - & 6 & $-0,24$ & 0,10 & $-1,23$ & 0,13 & $-0,33^{\mathrm{ns}}$ & 0,76 \\
\hline 2 & 6 & $-0,17$ & 0,32 & 7,11 & 0,2 & $0,89^{\text {ns }}$ & 0,41 & 6 & $-0,05$ & 0,40 & 3,34 & 0,06 & $1,07^{\mathrm{ns}}$ & 0,33 \\
\hline 3 & 6 & $-0,48$ & 0,00 & 2,30 & 0,1 & $1,66^{\mathrm{ns}}$ & 0,16 & 6 & $-0,06$ & 0,60 & 3,17 & 0,25 & $0,97^{\mathrm{ns}}$ & 0,38 \\
\hline 4 & 6 & $-0,19$ & 0,25 & 0,91 & 0,2 & $0,02^{\text {ns }}$ & 0,99 & 6 & $-0,16$ & 0,22 & $-0,38$ & 0,13 & $-0,29^{\mathrm{ns}}$ & 0,78 \\
\hline 5 & 6 & $-0,06$ & 0,03 & 0,12 & 0,0 & $0,36^{\mathrm{ns}}$ & 0,73 & 6 & $-0,22$ & 0,02 & $-0,63$ & 0,09 & $-0,88^{\mathrm{ns}}$ & 0,42 \\
\hline 6 & 6 & $-0,24$ & 0,10 & 0,51 & 0,1 & $0,70^{\mathrm{ns}}$ & 0,52 & 6 & $-0,22$ & 0,03 & $-0,45$ & 0,10 & $-0,78^{\mathrm{ns}}$ & 0,47 \\
\hline 7 & 6 & $-0,21$ & 0,02 & 0,54 & 0,1 & $1,90^{\mathrm{ns}}$ & 0,12 & 6 & $-0,10$ & 0,07 & $-0,24$ & 0,07 & $-0,71^{\mathrm{ns}}$ & 0,51 \\
\hline 8 & 6 & $-0,33$ & 0,03 & 0,68 & 0,1 & $1,71^{\mathrm{ns}}$ & 0,15 & 6 & $-0,12$ & 0,00 & $-0,48$ & 0,05 & $-2,13^{\mathrm{ns}}$ & 0,09 \\
\hline 9 & 6 & $-0,12$ & 0,12 & 0,45 & 0,1 & $0,81^{\mathrm{ns}}$ & 0,45 & 6 & $-0,25$ & 0,00 & $-0,71$ & 0,10 & $-1,76^{\mathrm{ns}}$ & 0,14 \\
\hline 10 & 5 & $-0,03$ & 0,11 & 0,24 & 0,1 & $1,16^{\mathrm{ns}}$ & 0,31 & 6 & $-0,07$ & 0,00 & $-0,15$ & 0,03 & $-1,55^{\mathrm{ns}}$ & 0,18 \\
\hline 11 & 5 & - & - & - & - & - & - & 5 & $-0,15$ & 0,03 & $-0,27$ & 0,06 & $-1,26^{\mathrm{ns}}$ & 0,28 \\
\hline 12 & - & - & - & - & - & - & - & 5 & $-0,10$ & 0,18 & 0,24 & 0,10 & $0,69^{\mathrm{ns}}$ & 0,53 \\
\hline 13 & - & - & - & - & - & - & - & 4 & $-0,10$ & 0,01 & $-0,25$ & 0,05 & $-1,62^{\mathrm{ns}}$ & 0,20 \\
\hline 14 & - & - & - & - & - & - & - & 4 & $-0,18$ & $-0,17$ & $-1,37$ & 0,01 & $37,93^{* *}$ & 0,02 \\
\hline \multicolumn{2}{|c|}{ Média } & $-0,18$ & 0,10 & 1,29 & 0,1 & - & - & - & $-0,14$ & 0,11 & 0,042 & 0,09 & - & - \\
\hline
\end{tabular}

No. Arv. é o número de árvores que apresentam de uma dada idade, ns teste não significativo a 5\%, * teste significativo a 5\%; ** teste significativo a $1 \%$. 
Tabela 3 - Resumo das análises das diferenças entre anatro convencional e digital para Mimosa scabrella e Pinus taeda, ao nível da área transversal anual.

Table 3 - Summary of the analyses of differences between conventional and digital stem analysis for Mimosa scabrella and Pinus taeda trees, at a level of annual cross-section area.

\begin{tabular}{|c|c|c|c|c|c|c|c|c|c|c|c|c|c|c|}
\hline \multicolumn{8}{|c|}{ Mimosa scabrella } & \multicolumn{7}{|c|}{ Pinus taeda } \\
\hline $\begin{array}{l}\text { Idade } \\
\text { (ano) }\end{array}$ & $\begin{array}{l}\text { No. } \\
\text { Arv. }\end{array}$ & $\begin{array}{l}\text { Menor } \\
\text { desvio }\end{array}$ & $\begin{array}{l}\text { Maior } \\
\text { desvio }\end{array}$ & $\begin{array}{l}\text { Desvio } \\
\text { médio }\end{array}$ & $\begin{array}{l}\text { Desvio } \\
\text { padrão }\end{array}$ & $\mathrm{t}_{(0,05)}$ & $p$ & $\begin{array}{l}\text { No. } \\
\text { Arv. }\end{array}$ & $\begin{array}{l}\text { Menor } \\
\text { desvio }\end{array}$ & $\begin{array}{l}\text { Maior } \\
\text { desvio }\end{array}$ & $\begin{array}{l}\text { Desvio } \\
\text { médio }\end{array}$ & $\begin{array}{l}\text { Desvio } \\
\text { padrão }\end{array}$ & $\mathrm{t}_{(0,05)}$ & $p$ \\
\hline & & $(\mathrm{cm})$ & $(\mathrm{cm})$ & $\%$ & $(\mathrm{~cm})$ & & & & $(\mathrm{cm})$ & $(\mathrm{cm})$ & $\%$ & $(\mathrm{~cm})$ & & \\
\hline 1 & 5 & $-1,45$ & 0,76 & 3,30 & 0,8 & $-0,29^{\mathrm{ns}}$ & 0,78 & 1 & 0,09 & 0,09 & - & - & - & - \\
\hline 2 & 6 & $-2,43$ & 1,16 & $-1,20$ & 1,5 & $-0,30^{\mathrm{ns}}$ & 0,78 & 6 & $-1,28$ & 0,06 & $-16,24$ & 0,5 & $-2,30^{\mathrm{ns}}$ & 0,07 \\
\hline 3 & 6 & $-5,62$ & 0,86 & $-2,99$ & 2,7 & $-1,01^{\mathrm{ns}}$ & 0,36 & 6 & $-2,02$ & 1,36 & $-4,27$ & 1,2 & $-1,09^{\mathrm{ns}}$ & 0,33 \\
\hline 4 & 6 & $-6,63$ & 1,29 & $-3,34$ & 2,9 & $-1,50^{\mathrm{ns}}$ & 0,19 & 6 & $-0,99$ & 0,66 & $-0,25$ & 0,6 & $-0,22^{\mathrm{ns}}$ & 0,83 \\
\hline 5 & 6 & $-1,63$ & 4,17 & 1,32 & 2,3 & $1,30^{\mathrm{ns}}$ & 0,25 & 6 & $-1,49$ & 0,93 & $-1,23$ & 1,0 & $-1,14^{\mathrm{ns}}$ & 0,31 \\
\hline 6 & 6 & $-1,99$ & 2,21 & $-1,69$ & 1,6 & $-1,17^{\mathrm{ns}}$ & 0,29 & 6 & $-2,12$ & 3,15 & $-0,52$ & 2,0 & $-0,33^{\mathrm{ns}}$ & 0,76 \\
\hline 7 & 6 & $-2,39$ & 4,21 & 0,29 & 2,4 & $0,52^{\mathrm{ns}}$ & 0,62 & 6 & $-3,49$ & 3,13 & $-0,81$ & 2,3 & $-0,61^{\text {ns }}$ & 0,57 \\
\hline 8 & 6 & $-3,80$ & 1,96 & $-1,75$ & 2,1 & $-1,57^{\mathrm{ns}}$ & 0,18 & 6 & $-4,99$ & 3,71 & $-0,44$ & 3,3 & $-0,29^{\text {ns }}$ & 0,78 \\
\hline 9 & 6 & $-2,95$ & 2,02 & $-1,69$ & 2,5 & $-0,94^{\mathrm{ns}}$ & 0,39 & 6 & $-5,73$ & 2,42 & $-1,73$ & 3,0 & $-1,52^{\mathrm{ns}}$ & 0,19 \\
\hline 10 & 6 & $-8,29$ & 7,02 & $-2,33$ & 5,7 & $-0,64^{\mathrm{ns}}$ & 0,55 & 6 & $-6,91$ & 1,32 & $-2,39$ & 3,5 & $-2,06^{\mathrm{ns}}$ & 0,09 \\
\hline 11 & 5 & $-10,65$ & 5,04 & $-3,48$ & 6,5 & $-1,26^{\mathrm{ns}}$ & 0,28 & 6 & $-6,84$ & 1,93 & $-2,02$ & 3,7 & $-1,84^{\mathrm{ns}}$ & 0,12 \\
\hline 12 & - & - & - & - & - & - & - & 5 & $-7,13$ & 2,99 & $-1,74$ & 4,3 & $-1,28^{\mathrm{ns}}$ & 0,27 \\
\hline 13 & - & - & - & - & - & - & - & 5 & $-6,80$ & 1,83 & $-1,76$ & 4,0 & $-1,55^{\text {ns }}$ & 0,20 \\
\hline 14 & - & - & - & - & - & - & - & 4 & $-6,67$ & 2,44 & $-1,68$ & 4,7 & $-1,00^{\mathrm{ns}}$ & 0,39 \\
\hline \multicolumn{2}{|c|}{ Média } & $-4,35$ & 2,79 & $-1,23$ & 2,82 & - & - & - & $-4,34$ & 1,99 & $-2,70$ & 2,62 & - & - \\
\hline
\end{tabular}

No. Arv. é o número de árvores que apresentam de uma dada idade, ${ }^{\text {ns }}$ teste não significativo a 5\%, * teste significativo a $5 \%$; $* *$ teste significativo a $1 \%$.

Tabela 4 - Resumo das análises das diferenças entre anatro convencional e digital para Mimosa scabrella e Pinus taeda, considerando o volume anual.

Table 4-Summary of the analysis of differences between conventional and digital stem analysis for Mimosa scabrella and Pinus taeda trees, considering annual volume.

\begin{tabular}{|c|c|c|c|c|c|c|c|c|c|c|c|c|c|c|}
\hline \multicolumn{8}{|c|}{ Mimosa scabrella } & \multicolumn{7}{|c|}{ Pinus taeda } \\
\hline $\begin{array}{l}\text { Idade } \\
\text { (ano) }\end{array}$ & $\begin{array}{l}\text { No. } \\
\text { Arv. }\end{array}$ & $\begin{array}{l}\text { Menor } \\
\text { desvio }\end{array}$ & $\begin{array}{l}\text { Maior } \\
\text { desvio }\end{array}$ & $\begin{array}{l}\text { Desvio } \\
\text { médio }\end{array}$ & $\begin{array}{l}\text { Desvio } \\
\text { padrão }\end{array}$ & $\mathrm{t}_{(0,05)}$ & $p$ & $\begin{array}{l}\text { No. } \\
\text { Arv. }\end{array}$ & $\begin{array}{l}\text { Menor } \\
\text { desvio }\end{array}$ & $\begin{array}{l}\text { Maior } \\
\text { desvio }\end{array}$ & $\begin{array}{l}\text { Desvio } \\
\text { médio }\end{array}$ & $\begin{array}{l}\text { Desvio } \\
\text { padrão }\end{array}$ & $\mathrm{t}_{(0,05)}$ & $p$ \\
\hline & & $(\mathrm{cm})$ & $(\mathrm{cm})$ & $\%$ & $(\mathrm{~cm})$ & & & & $(\mathrm{cm})$ & $(\mathrm{cm})$ & $\%$ & $(\mathrm{~cm})$ & & \\
\hline 1 & 6 & $-71,03$ & 47,82 & $-5,60$ & 52,9 & $0,18^{\mathrm{ns}}$ & 0,86 & 6 & 15,87 & 15,87 & $-2,05$ & 17,696 & $-0,46^{\mathrm{ns}}$ & 0,67 \\
\hline 2 & 6 & $-70,49$ & 123,36 & 1,94 & 74,5 & $0,65^{\text {ns }}$ & 0,55 & 6 & $-140,22$ & 107,52 & $-3,25$ & 99,7 & $-0,79^{\mathrm{ns}}$ & 0,46 \\
\hline 3 & 6 & $-454,84$ & 508,62 & 1,40 & 359,5 & $0,20^{\mathrm{ns}}$ & 0,85 & 6 & $-304,28$ & $-38,62$ & $-5,20$ & 96,2 & $35^{*}$ & 0,01 \\
\hline 4 & 6 & $-196,56$ & 493,01 & 1,34 & 237,5 & $1,55^{\mathrm{ns}}$ & 0,18 & 6 & $-281,96$ & 85,28 & $-0,46$ & 153,5 & $-0,51^{\mathrm{ns}}$ & 0,63 \\
\hline 5 & 6 & $-177,83$ & 674,98 & 1,42 & 318,4 & $1,64^{\mathrm{ns}}$ & 0,16 & 6 & $-1120,47$ & 86,86 & $-3,21$ & 423,5 & $-2,24^{\mathrm{ns}}$ & 0,07 \\
\hline 6 & 6 & $-301,94$ & 983,07 & 0,79 & 503,6 & $1,22^{\mathrm{ns}}$ & 0,27 & 6 & $-705,53$ & 163,12 & $-1,88$ & 358,7 & $-2,61 *$ & 0,05 \\
\hline 7 & 6 & $-126,12$ & 1279,15 & 1,42 & 564,7 & $2,21^{\mathrm{ns}}$ & 0,08 & 6 & $-1111,89$ & 65,61 & $-1,98$ & 404,1 & $-3,72 *$ & 0,01 \\
\hline 8 & 6 & $-1199,82$ & 996,86 & 0,20 & 817,9 & $0,18^{\mathrm{ns}}$ & 0,86 & 6 & $-1978,80$ & $-113,45$ & $-2,09$ & 852,5 & $-2,62 *$ & 0,05 \\
\hline 9 & 6 & $-940,67$ & 773,42 & $-0,17$ & 678,6 & $-0,06^{\text {ns }}$ & 0,95 & 6 & $-2602,90$ & $-571,77$ & $-2,26$ & 977,5 & $-3,29 *$ & 0,02 \\
\hline 10 & 6 & $-657,46$ & 2155,75 & 0,66 & 935,3 & $1,17^{\mathrm{ns}}$ & 0,29 & 6 & $-3462,98$ & 101,98 & $-1,79$ & 1488,6 & $-2,19^{\mathrm{ns}}$ & 0,08 \\
\hline 11 & 5 & $-2192,59$ & 252,70 & $-1,06$ & 911,4 & $-1,75^{\text {ns }}$ & 0,14 & 6 & $-4351,92$ & 509,61 & $-1,76$ & 1934,3 & $-2,05^{\mathrm{ns}}$ & 0,10 \\
\hline 12 & - & - & - & - & - & - & - & 5 & $-5726,53$ & 141,78 & $-1,51$ & 2377,4 & $-1,48^{\text {ns }}$ & 0,21 \\
\hline 13 & - & - & - & - & - & - & - & 5 & $-5453,06$ & 309,32 & $-1,54$ & 2140,7 & $-1,99^{\mathrm{ns}}$ & 0,12 \\
\hline 14 & - & - & - & - & - & - & - & 4 & $-2123,35$ & 81,67 & $-0,99$ & 952,4 & $-2,13^{\text {ns }}$ & 0,12 \\
\hline \multicolumn{2}{|c|}{ Média } & $-580,85$ & 753,52 & 0,21 & 495,85 & - & - & - & $-2096,29$ & 67,48 & $-2,14$ & 876,91 & - & - \\
\hline
\end{tabular}

No. Arv. é o número de árvores que apresentam de uma dada idade, ${ }^{\text {ns }}$ teste não significativo a 5\%, * teste significativo a $5 \%$; ** teste significativo a $1 \%$.

Revista Árvore, Viçosa-MG, v.37, n.2, p.329-337, 2013 
O uso do programa ArcView para o procedimento de vetorização, que possibilitou o cálculo dos raios dos anéis de crescimento em cada disco, foi fácil, porém trabalhoso e demorado, requerendo profissional qualificado. A possibilidade de exportar os dados gerados pelo ArcView para uma planilha eletrônica agilizou os cálculos comparativos, pois no Excel foi mais fácil a organização e já existem funções para automatizar tais cálculos.

Na Tabela 1, referente aos diâmetros, pode-se observar que o desvio médio das duas espécies foi negativo quando o valor da anatro digital foi mais elevado e tendeu a ser maior nos primeiros anos. Também pode ser observado, nessa tabela, que as idades encontradas para as árvores estudadas foram de 10 e 11 anos para a M. scabrella e variaram de 12 a 15 anos para o P. taeda. Das seis árvores selecionadas de cada espécie, nem todas puderam ser usadas em todas as idades pretendidas. Para $M$. scabrella, uma das árvores apresentou o anel correspondente ao primeiro ano de crescimento, finalizando antes do dap, e outra não tinha o anel correspondente ao décimo primeiro ano de crescimento. Já em $P$. taeda foram cinco árvores sem dap no primeiro ano de crescimento e apenas duas árvores tinham o anel de crescimento correspondente ao décimo quinto ano. Assim, foram comparadas apenas as idades representadas pelos anéis presentes em no mínimo três árvores. Dessa forma, com um mínimo de três repetições o teste estatístico já apresenta certa credibilidade.

Por meio do teste $t_{(0,05)}$, observou-se que as diferenças entre a anatro manual e a digital não foram significativas e a probabilidade $P\left(\mathrm{t}_{\mathrm{n}, 1}>\mathrm{t}^{\mathrm{c}}{ }_{\mathrm{n}-1}\right)$ reforça a possibilidade de que quaisquer diferenças observadas podem ser consideradas como meramente devidas a flutuações das amostras provenientes da mesma população, o que equivale dizer que não se rejeita a hipótese nula $\left(\mathrm{H}_{\mathrm{o}}\right)$. Então, a anatro digital foi perfeitamente aplicável à medição de anéis de crescimentos de $M$. scabrella e P. taeda.

Uma possível explicação para as maiores diferenças entre a anatro convencional e a digital, nas idades mais jovens, quando se compararam os diâmetros, é uma característica da anatro convencional que demanda uma régua métrica para a medição dos raios dos anéis. Isso limita o tamanho do raio a determinada marca de milímetro, ou seja, se o raio terminar entre duas marcas de milímetro na régua, deve-se optar pela marca mais próxima. Essa diferença, por menor que seja, em raios pequenos como os dos primeiros anos, tem representatividade maior. O mesmo não ocorre na anatro digital, porque a medição do raio é feita no ponto exato onde este termina. Tal fato põe a anatro digital em vantagem quando se refere à medição de anéis de crescimento. Isso foi evidenciado também por Rosot et al. (2001a, b), que compararam áreas transversais entre anéis, obtidas por imagens digitais e por outros procedimentos, e obtiveram diferenças médias, de um anel para outro, de $0,23 \%$ e $-0,3 \%$, contrastando com as encontradas neste trabalho: $-0,49 \%$ para $M$. scabrella e $-1,28 \%$ para $P$. taeda.

Como a área transversal de uma árvore é função do diâmetro, espera-se que as diferenças apresentadas para o diâmetro exerçam influência na área transversal. É o que pode ser observado na Tabela 3, onde o desvio médio em porcentagem é aproximadamente o dobro do desvio médio em porcentagem do diâmetro, tanto para $M$. scabrella quanto para $P$. taeda. Isso evidencia a necessidade de que a medição dos raios dos anéis de crescimento seja a mais precisa possível, pois seus valores irão influenciar a área transversal e, consequentemente, o volume, levando a conclusões equivocadas baseadas em dados que podem estar sub ou superestimados. Ainda na Tabela 3, pode-se observar que a diferença entre a anatro digital e a convencional das áreas transversais de cada ano de crescimento não foi significativa nas duas espécies estudadas.

Como a altura de cada ano de crescimento foi calculada pelo método do paralelismo ao anel anterior, essa altura que cada ano atinge é dependente do tamanho do raio desse anel anterior. Se a diferença no tamanho do raio do anel anterior, gerada pelas anatros, for muito pequena, então o método do paralelismo vai resultar em alturas iguais ou muito próximas para cada uma das anatros. Assim, as diferenças não significativas obtidas para os diâmetros contribuíram para a geração de diferenças não significativas também na altura dos anéis de crescimento. Por isso, alguns anos de crescimento obtiveram alturas iguais para as anatros digital e convencional (Tabela 2) e, inclusive, o primeiro ano de crescimento de $M$. scabrella obteve alturas idênticas pelas duas anatros para as seis árvores, o que impossibilitou a comparação nesse ano. Já no último ano de crescimento se sabe que a altura atingida é a altura total da árvore. Então, no último ano não houve

Revista Árvore, Viçosa-MG, v.37, n.2, p.329-337, 2013 
diferença de altura resultante de cada anatro, não cabendo análises.

Na Tabela 4, pode-se observar que a diferença em volume, entre uma anatro e outra, tende a diminuir com o aumento da idade. Essa diferença sofreu influência das diferenças apresentadas nas áreas transversais das seções usadas, porém a comparação entre volumes obtidos através das duas anatros resultou em diferenças não significativas para a $M$. scabrella. Já para o $P$. taeda, em algumas idades, essa diferença foi significativa.

Assumindo todas as idades, a anatro digital apresentou diferença média em volume $0,21 \%$ superior à anatro convencional para a $M$. scabrella e para o $P$. taeda, com média $2,14 \%$ para menor. Considerando que as duas técnicas de anatro foram aplicadas em discos já secos, não ocorreram as diferenças decorrentes da retração volumétrica no processo de secagem, o que pode ter influenciado os resultados de Rosot et al. (2003), porque esses autores aplicaram a anatro digital em discos recém-cortados e a anatro convencional em discos secos. Eles observaram que a anatro digital apresentou diferença média em volume, em todas as idades, de aproximadamente $7 \%$ a mais que a convencional e, segundo suas análises, essa diferença foi significativa.

Confrontando os resultados de Rosot et al. (2003) com os encontrados nesta pesquisa para $P$. taeda e considerando a técnica digital como a mais acurada na delimitação e medição dos anéis, supõe-se que a diferença média de $2 \%$ para o volume é devida à medição dos anéis com a régua métrica ou a algum erro de interpretação do limite dos anéis no momento da medição. Já em Rosot et al. (2003) os 7\% de diferença indicam que, além desses possíveis erros, há a diferença da retração volumétrica do P. taeda no processo de secagem, que foi pequena, considerando que há registros de retração em volume de diferentes idades para o Pinus elliottii e Pinus taedade 10 a 12\% (OLIVEIRA et al., 2006), aproximadamente 14\% (PALMA; BALLARIN, 2003) e cerca de $11 \%$ (BOLZON DE MUÑIZ, 1993). Isso reforça a vantagem da anatro digital, pois dela se obtém o volume verde de cada ano de crescimento, enquanto da anatro convencional é obtido o volume seco, sendo este usado nos estudos de crescimento como verde, subestimando o crescimento das árvores ao longo dos anos.

Embora tenham sido observadas diferenças significativas para algumas das idades estudadas, no geral se pode estabelecer a anatro digital como avanço significativo no estudo do crescimento passado de árvores. A contribuição dessa técnica reside na possibilidade de medir com maior precisão o diâmetro de cada anel de crescimento em fatias-amostra de árvores e na automação da técnica da anatro, já que bastaria inserir uma imagem da fatia no programa e, com os comandos adequados, os anéis seriam rapidamente identificados na imagem. O operador teria apenas que resolver os casos em que um anel não fosse adequadamente identificado ou se ocorressem falsos anéis.

A principal vantagem da anatro digital, enfatizada por Rosot et al. (2003), que seria fotografar os discos no campo logo após o corte, portanto sem secá-los e lixá-los, utilizando apenas suas imagens para a anatro, não foi avaliada neste trabalho, visto esses autores já terem concluído que ela foi boa. Porém, entendese que esse procedimento é possível para aquelas espécies que apresentam anéis de crescimento muito bem diferenciados. O procedimento de secar e lixar discos na técnica da anatro serve justamente para melhor evidenciar o limite de cada anel de crescimento. Esse limite é difícil de observar com segurança na fatia não lixada, porém se acredita que tratamentos nas imagens das fatias que intensifiquem o contraste entre os anéis facilitariam sua delimitação. Mesmo assim, o procedimento de substituir as fatias físicas por imagens precisa ser mais estudado.

O trabalho de Rosot et al. (2003) resultou em um programa de computador que reúne as ferramentas necessárias para a identificação e medição dos anéis de crescimento nas imagens, como tentativa de facilitar o emprego da técnica, já que, da forma como foi elaborada pelos autores, necessitaria de pessoa treinada para usar ferramentas de Sistema de Informações Geográficas (SIG), o que seria caro. Trata-se do programa "Anatro Livre”, que atualmente é disponibilizado em <http:/ /www.cnpdia.embrapa.br/labimagem/index.php>.

\section{CONCLUSÕES}

A técnica da análise de tronco digital foi melhor para delimitar anéis de crescimento e automatizar os cálculos.

A análise de tronco digital precisa de programas de computador específicos e pessoa treinada para manuseá-los, o que pode ter custo alto enquanto a técnica não for aprimorada. 


\section{REFERÊNCIAS}

BARUSSO A. P. A determinação de funções de crescimento mediante análise de tronco. 1977.133f. Dissertação (Mestrado em Ciências Florestais) - Setor de Ciências Agrárias, Universidade Federal do Paraná, Curitiba, 1977.

BOLZON DE MUÑIZ, G. I. Caracterização e desenvolvimento de modelos para estimar as propriedades e o comportamento na secagem da madeira de Pinus elliotti e Pinus taeda L. 1993.235f. Tese (Doutorado em Ciências Florestais) - Setor de Ciências Agrárias, Universidade Federal do Paraná, Curitiba, 1993.

\section{FERREIRA, A. T. B.; TOMAZELLO FILHO, M.} Caracterização dos anéis de crescimento de árvores de Pinus caribaea var. hondurensis Barr. et Golf. por densitometria de raios X. Scientia Forestalis, v.37, n.83, p.287-298, 2009.

FINGER C. A. G. Fundamentos da biometria florestal.Santa Maria: UFSM,1992.269p. (CEPEF/FATEC).

MACHADO, S. A. et al.Comparison of methods for estimating heights from completly stem analysis data for Pinus taeda. Ciência Florestal,no prelo.
OLIVEIRA, F. L. et al.Propriedades da madeira de Pinus taeda L. em função da idade e da posição radial na tora. Revista Instituto Florestal, v. 18, n. único, p.59-70, 2006.

PALMA, H. A. L.; BALLARIN, A. W. Propriedades de contração na madeira juvenil e adulta de Pinus taeda L. Scientia Forestalis, n.64, p.13-22, 2003.

PRODAN, M. et al. Mensura forestal. San Jose: IICA, 1997. 561p.(Investigacion y educacion en desarrolo sostenible)

ROSOT, M. A. D.; DISPERATI, A. A.; FIGUEIREDO FILHO, A.Medição da área de anéis de crescimento usando imagens digitais. Revista Árvore, v.25, n.1, p.79-88, $2001 \mathrm{a}$.

ROSOT, M. A. D.; DISPERATI, A. A.; FIGUEIREDO FILHO, A. Medição de áreas transversais em análise de tronco através de técnicas de análise de imagem: uma simulação. Revista Árvore, v.25, n.2, p.231-239, 2001 b.

ROSOT, M. A. D. et al.Análise de tronco digital: uma nova metodologia para a medição de anéis de crescimento.Floresta, v.33, n.3, p.235-255, 2003. 
